\title{
Investigation of in-School Factors Affecting Distributed Leadership Practices
}

\author{
Çiğgdem ÇAKIR *1 (D) Metin ÖZKAN 2 (D) \\ ${ }^{1}$ Kadriye Abdülmecit Özgözen Middle School, Gaziantep, Turkey, cigdemcakir1905@gmail.com \\ ${ }^{2}$ Gaziantep University, Department of Educational Sciences, Gaziantep, Turkey, ozkanmetin@gmail.com \\ * Corresponding Author: cigdemcakir1905@gmail.com
}

\begin{tabular}{l}
\hline Article Info \\
\hline \\
Received: 29 June 2019 \\
Accepted: 19 August 2019 \\
\\
Keywords: Leadership, Distributed \\
Leadership, Shared Leadership, \\
Shared Management, Educational \\
Administration
\end{tabular}

DOI: $10.18009 /$ jcer.584459

Publication Language: English

\begin{abstract}
The aim of this study is to identify the distributed leadership levels in public secondary schools (under the Ministry of National Education) and explore the in-school factors affecting distributed leadership practices based on teachers' opinions. The research is designed based on a mixed approach. In the quantitative dimension, the sample group consists of 736 teachers from 27 different secondary schools in the Gaziantep Province. In the qualitative dimension, the focus group is composed of 24 participant teachers. The Distributed Leadership Scale was used to identify distributed leadership levels of schools. In the qualitative dimension, a semi-structured interview form developed by the researchers was applied as the evaluation instrument. According to teachers' opinions, the rarest subdimension of distributed leadership at schools is the "common goals", while the most frequently seen is the "cooperation and trust" subdimension. The findings obtained through interviews show that risk-taking, managerial support, learning culture, accountability relations, communication, professional development, facilitating role of the administration and the organizational culture are positive factors that support distributed leadership, while absence of these factors poses a barrier to management activities.
\end{abstract}

To cite this article: Çakır, Ç. \& Özkan, M. (2019). Investigation of inschool factors affecting distributed leadership practices. Journal of Computer and Education Research, 7(14), 383-417. DOI: 10.18009/jcer.584459

\section{Introduction}

Together with technologic advancement and the subsequent rapidly changing situations and transformations, the future has turned out not to be predictable. Therefore, reconsideration of different approaches and models of leadership that have been effectively adopted for ages has been a significant necessity for today's researchers over time. Accordingly, it can be suggested that a strong trend emerged in the $21^{\text {st }}$ century to pursue new definitions, explanations and interpretations of organizations. This trend has also brought about novel approaches to the phenomenon of leadership. The recent trends seen in the literature about leadership are generally relevant to the common mind-oriented organizations. Leadership was considered as a proper treatment to all organizational 
illnesses in 1990s and 2000s (Pounder, Ogawa \& Adams, 1995). In this period of time, it also replaced the concept of management and became the focus in the literature of organizational research. As opposed to the traditional internal management systems, the literature started to concentrate on individuals (emotions, needs, motivation) and communities (teamwork, cooperation) (Kotter, 1990). It is due to the fact that organizations were no longer seen as machine organizations as they were according to the traditional managerial models, but as chaotic systems that are affected by social networks and the impact of processes caused by their interaction. In this regard, the idea of the one and only heroic leader model has been replaced by a novel model that attaches values to every individual and supports the idea of a common mind that associates knowledge, skills, experience and other characteristics of each individual through counseling and guidance to achieve organizational targets (Özkan \& Çakır, 2017).

The idea of a common mind in organizational management was first raised by Gibb (1947, 1954), a social psychologist from Australia. In subsequent years, Drucker (1959) emphasized the idea that the survival of an organization depends on the collective contribution of its employees. Fiedler (1964) emphasized that relations among employees may change to achieve the organization's predetermined targets and the principle that each employee may take a role in leadership regardless of status. In light of this point of view, the loosely unified system theory and the 1960s' movement of standards have led professionals to pay attention to personal characteristics and opened a gate to each employee to participate in leadership practices (Elmore, 2000). After the maturation of discussions within half a century, the distributed leadership notion, which started to be suggested by the common mind in 1990s, had been intensely studied by the researchers in the organization management literature.

The distributed leadership term does not refer to delegation of authority but an extension of the leadership notion over personal efforts of each employee in an organization and a social distribution in which leadership practices are ensured by interpersonal interactions (Harris, 2004b). From this point of view, leadership is a function of organizational targets and values as well as the methods used to achieve these targets; in other words, a function of a whole organization. Thus, leadership should not refer to a single person but an activity that has to be distributed (Gibb, 1947; 1954). Accordingly, this 
approach considers leadership as the collective contribution of leaders and each relevant individual to the organization (Printy, 2008).

This fact is also seen in schools in terms of the changing literature about organizations and leadership. Together with the change in the approaches to leadership as a concept, unlike the traditional idea that puts a single individual into a position that controls an increasingly more hierarchic structure, studies have been centered upon the fact that leadership in schools is not under the monopoly of school principals and significant findings have proved that teachers, parents and other employees also play a significant role in this regard (Harris \& Muijs, 2005; Smylie \& Denny, 1990). As a result, a leadership style that encourages leaders to share responsibilities and authority has been a popular topic of discussion, while the school headship has started to be reevaluated in consideration of activities distributed among different individuals and situations, as well as the interactions between these different factors (Camburn, Rowan \& Taylor, 2003; Spillane, 2006).

The distributed leadership approach involves all stakeholders of schools. In this regard, teachers' role in leadership practices may particularly be emphasized. Accordingly, the knowledge required for the development of a school is not just provided by its managers but also the teachers, who carry out the educational activities (Elmore, 2000). In line with this point of view, the European Policy Network on School Leadership defines the term of distributed leadership as a process that uses the distributed leadership model as a strategic tool to benefit knowledge and skills peculiar to teachers, students, other employees and parents so as to achieve common educational outputs (Spillane, 2006). Hereby, the target is to build a consistent whole from the differences in fields and levels of expertise of individuals. The guidance and counseling activities carried out during this process, within the limits of the given expertise, are considered as a glue that attaches the framework of common values and common aims or targets (Bennett, Wise, Woods \& Harvey, 2003a, b; Bolden, 2011; Elmore, 2000; Woods, Bennett, Harvey \& Wise, 2004).

The organizational structure and common goals of schools, cooperation and trust among employees, division of responsibility, motivation of employees and their initiatives are all significant dimensions of the distributed leadership (Özkan \& Çakır, 2017). Moreover, in organizational settings there may be facilitative or obstructive situations or structures behind this leadership approach. Risk-taking (Grenda, 2011), self-esteem and confidence (MacBeath et al. 2004; Singh, 2014), accessibility of material and human resources (Singh, 
2014), learning culture, staff development and accountability (MacBeath et al., 2004), different types of managerial support for teachers (Harris, 2002) and acting in accordance with a plan at school (Avolio, 2011; Grenda, 2011) are considered as facilitative factors. It is clearly seen that the Turkish Education System, which requires further development to achieve its target to raise a nation equipped with the modern skills of the 21st century, needs the contributions of all stakeholders for leadership processes. The way to ensure efficiency at schools, which constitute the execution area of education policies, is to optimize the contribution of each relevant individual. Indeed, as seen in Turkey 2023 Educational Vision Document the policymakers' effort of creating a system that recognizes students, teachers, parents and schools as key elements and opens the way for all stakeholders to take part in education-related activities in terms of both the schools and the system as a whole is an indication of this way. In this regard, tracking down the leadership at schools and identifying the supportive and obstructive factors and taking these elements into consideration are considered significant in terms of creating common mind.

The roots of distributed leadership refer Gibb's $(1947,1954)$ studies, while the researchers focused on its theoretical background only in 1990s (Archer, 1995; Bennett et al. 2003a, b; Elmore, 2000; Fielding, 1999; Gronn, 2000; MacBeath et al. 2004; Mahoney \& Moos, 1998; Spillane, 2005; Spillane, Halverson \& Diamond, 2001; Wallace \& Hall, 1994; Woods et al. 2004); and it became a subject of empirical studies in 2000's (Chen, 2007; Davis, 2009; ESHA, 2013; Gordon, 2005; Grenda, 2011; Heck \& Hallinger, 2009; Singh, 2014; Smith, 2007; Williams, 2011). Specifically, in the Turkish literature, theoretical aspects of distributed leadership have been studied by a limited number of researchers (Baloğlu, 2011a, 2011b) and its empirical aspects have been studied more as a scale adaptation with a limited number of scale development attempts and will become a subject for certain thesis dissertations (Adıgüzelli, 2016; Ağırdaş, 2014; Arabac1, Karabatak \& Polat, 2016; Baloğlu, 2012; Kılınç, 2014; Korkmaz \& Gündüz, 2011; Özdemir, 2012; Özkan \& Çakır, 2017; Y1lmaz \& Turan, 2015). As a result of the literature review, it was seen that there is no study to determine the elements that support and prevent the implementation of distributed leadership within the school. With the importance mentioned above and to close the emprical study deficit this study was designed with mixed approach. The first (quantitative) section of this study aims to identify the distributed leadership levels of schools taking the opinions of teachers into account. The second (qualitative) section of the study, on the other hand, aims to identify the 
opinions of secondary school teachers, which have high or low levels of distributed leadership, about the factors regarding the distributed leadership practices. For the purpose of the study, the following questions were sought:

1. What are the distributed leadership levels of schools?

2. What are the factors regarding the distributed leadership practices in high and low level schools?

\section{Method}

This section explains the model, population, sample and work groups, data collection instruments, data collection and analysis processes of the study.

The Model of Research

The study was designed with a mixed approach using both the quantitative and qualitative research methods. According to Johnson and Onwuegbuzie (2004), a mixed research method has the main goals of diversification, complementarity, initialization, development and extension. In this study, the mixed research method was used to ensure a comprehensive and clear explanation of distributed leadership as well as to diversify and complete the data obtained throughout the process. Creswell (2012) classifies the mixed research design under four main titles, namely, the embedded design, the explanatory design, the exploratory design and the parallel mixed design. This study adopted the explanatory design, also called as sequential mixed research design, as first was collected as quantitative data and then some qualitative data to explain the former (Creswell \& Plano Clark, 2007).

In its quantitative dimension, the single screening model was used as a descriptive method in accordance with the research question. The single screening model is a screening model that aims to describe the variables regarding the occasion, material, individual, group, institution, subject, unit or condition in question (Karasar, 2012, p. 79). In its qualitative dimension, a multiple case study was conducted. Multiple case studies examine a single subject through multiple units of analysis. Hereby, the states are selected purposively so as to reveal different perspectives about the subject. In multiple case studies, it is significant for the researcher to follow the same steps for each state (Creswell, 2013, p. 99). In this study, researchers took care of following the same steps for each state. 
Population, Sample and Study Group

The population of the study's quantitative dimension consists of 147 formal secondary schools in Gaziantep province and 5073 permanent and contracted teachers working at those schools in the 2017-2018 academic year. The study uses criterion sampling, which is a purposive sampling method. Criterion sampling is the process in which samples are taken from people, occasions, objects or situations that meet the predetermined criteria (Büyüköztürk et al., 2012, p. 91). The sustainability of administrative staff is a significant matter to ensure an effective distributed leadership (Clark, 2007, p. 128). Accordingly, the sampling criterion for the principals within the scope of the study was at least two years of employment at the same school, while the criterion for the teachers was determined as working at least one year together with the same principal to be able to comment about him/her. Before the selection of schools, researchers received necessary permissions from the Governorate of Gaziantep Province, met with the Research and Development Team at Gaziantep Provincial Directorate of National Education and then the names, addresses, principal's length of employment at the same school and number of teachers were identified. Next, the measurement instrument was applied in 27 schools that met the predetermined criteria.

The sample measurement formula developed by Büyüköztürk et al. (2012, p. 94) was used to choose the number of teachers who will be involved in the study population. Finally, 358 teachers in total were chosen as members of the sample group. However, as the study had planned to conduct interviews on a voluntary basis and considering the possibility of data loss during submission of scales and the computerization of statistics, the number of participants was chosen higher that the aforementioned population of sample group and 850 teachers were contacted. 763 of the scales given to the participant teachers were returned and 27 of them were eliminated due to absence of required data. Eventually, the analysis was conducted with 736 scale forms in total. The sample group represents nearly $15 \%$ of the population. $86.1 \%$ (634) of the participant teachers had $1-5$ years, $11 \%$ (81) had $6-10$ years and $2.9 \%$ had 11 or more years of experience at the school they currently work for.

During the qualitative dimension of the process, the two-stage sampling method was applied to choose the participants. In the first stage, the criterion sampling method was used as a purposive sampling method, while in the second stage the maximum diversity sampling approach was adopted. The reason for using the criterion sampling method was to be able to 
analyze all states that meet the predetermined criteria. On the other hand, the maximum diversity sampling approach aimed to ensure maximum diversity with a large range of associated individuals (Yıldırım \& Şimşek, 2013). In this regard, the quantitative part of this study was based on the average score distribution of the selected 27 schools in order to rely the selection process for the qualitative part on certain criteria and ensure the sample diversity. Levels (low or high) of distributed leadership were considered as a criterion, two schools were not involved in the qualitative research process due to high levels of distributed leadership, while two other schools were eliminated due to low levels. Therefore, it was aimed to collect data from teachers of different branches (social sciences, life sciences, classroom teachers, pre-school teachers and other branches) working at schools with different levels of distributed leadership in order to ensure the diversity. 24 teachers in total were interviewed during the study with 6 teachers from each school. In this way, this study aimed to collect more detailed information from different individuals at the school. 24 teachers from four different schools, who participated in the qualitative research, were from 11 different branches (Physical Education, English Language, Mathematics, Religious Culture and Moral Knowledge, Technology and Design, Information Technologies, Visual Arts, Music and Social Studies). The seniority of participant teachers varies between 3 and 20 years and only one of the teachers had previously been trained in leadership.

\section{Data Collection Tools}

The quantitative data was collected with the "Personal Information Form" and the “Distributed Leadership Scale” developed by Özkan and Çakır (2017).

Personal Information Form was developed to identify length of employment variable regarding the participant teachers, while Distributed Leadership Scale (DLS) aims to identify distributed leadership levels in public schools under the Ministry of National Education, was developed by Özkan and Çakır (2017). It is a four-point Likert-type scale. The development process was carried out with 868 secondary school teachers from Şahinbey and Şehitkamil districts of Gaziantep province. The scope and face validity of this scale were evaluated by experts in the relevant field. The construct validity was tested by the Exploratory Factor Analysis (EFA) and the Confirmatory Factor Analysis (CFA). The EFA yielded to a five factor construct that explains $62.465 \%$ of the total variance. The factor model suggested by the EFA was tested by the CFA. As a result of the CFA, the Root Mean Square Error of 
Approximation (RMSEA) value was obtained as 0.063 , while the Comparative Fit Index (CFI) value was obtained as 0.98 among other compliance indices. The total Cronbach's Alpha internal consistency coefficient of the scale was calculated as 0.87 and the split-half reliability coefficient was found as 0.92. As a result of the study, a five factor (formal structure, unity of purpose, cooperation and trust, division of responsibility and motivation and initiative) was created with 32 items. This study re-questioned the structure and reliability of the DLS in order to provide evidence of reliability for the data collected from the participants. The 32 items and five factor construct of the original scale was tested by the CFA. The model was tested by the Maximum Likelihood method at a significance level of 0.05 . The analyzed Normed Fit Index (NFI)-0.98, Tucker Lewis Index (NNFI-TLI)-0.98, CFI-0.98, Relative Fit Index (RFI)-0.98 and Standardized Root Mean Square Residual (SRMR)-0.045 compliance values were found within positive compliance limits, while Adjustment Goodness of Fit Index (AGFI)-0.85 and RMSEA-0.061 values were identified within the acceptable compliance limits. Factor load values of the items in the scale were more than 0.30 . The Cronbach's Alpha value was obtained as 0.96. Depending on these findings, the DLS was found valid and reliable for the study.

Within its second section, interviews were planned with teachers at four different schools in order to collect qualitative data. In line with the relevant body of literature, the researchers developed a semi-structured interview form. As the qualitative dimension of the study was based upon the quantitative part, the findings obtained throughout the latter influenced the development of this interview form. The reliability of the semi-structured interview form was evaluated by experts in the field. In order to test the comprehensibility of the questions, pilot interviews were conducted with two teachers from the focus group and the form was finalized considering the feedback obtained during this process. The semistructured interview form consists of three main sections, namely, setting, personal information and questions about distributed leadership. During the development process of the interview form, the themes and codes were created using the conceptual framework of distributed leadership. The list of themes and codes were modified to some extent during the analysis. 


\section{Data Collection}

As the field of distributed leadership spans over a large area of studies (Bennet et al., 2003a, b; Bolden, 2011; Chen, 2007; Spillane, 2006; Woods et al., 2004), the quantitative dimension of the study aimed to communicate the scale to teachers of different branches from each target school. Considering the number of different branches taught at schools, at least 14 scale forms and an authorized additional file were created. The researchers delivered 27 files to schools by hand and informed the staff about use of the measurement instrument. The quantitative data collection process was completed within around one month.

Within the qualitative dimension of the research, semi-structured interviews were conducted with 24 teachers from four different schools (two with lowest levels of distributed leadership, the other two with highest levels of distributed leadership) chosen among the sample group where the quantitative data were collected. The interviews were conducted at schools in order to ensure a natural setting where the teachers can express themselves comfortably. During this process, the interviewees were informed about the aim of the interviews and that all data obtained in this process would be used in accordance with the relevant codes of conduct. Interviews were conducted face-to-face on the dates scheduled in cooperation with the participants and lasted for 23-47 minutes. Taking the factors that increase the quality of interviews into account, the participants were asked for permission to take audio records during the interviews and all of them responded positively. After that, these audio records were transcribed using a computer and different codes were assigned to the schools and participant teachers within this process. Codes like LLDL1, LLDL2, HLDL1 and HLDL2 were utilized to symbolize the schools. Herein, LLDL1 refers to the first qualitatively analyzed school with a low level of distributed leadership, while HLDL1 means the first qualitatively analyzed school with a high level of distributed leadership. The " $\mathrm{T}$ " sign was used to identify the participant teachers who work at these aforementioned schools. Numbers from 1 to 6 was put beside the "T" sign in order to symbolize the order of teachers who participated in the qualitative research.

Data Analysis 
Within the quantitative data analysis process, descriptive statistics (mean, standard deviation) were used to identify perception levels of the teachers about subdimensions of distributed leadership (formal structure, comman goals, cooperation and trust, shared responsibility, encouragement and initiative).

During the qualitative data analysis process, the descriptive analysis was used as a qualitative data analysis method. The data, transferred to a MS Word file to see datasets clearly, was analyzed and significant analyzable datasets were identified in line with the predetermined framework. Subsequently, the data codification was initiated according to the identified themes. The themes and codes were correlatively explained and interpreted and the results were revealed in accordance with the research objective.

\section{Validity and Reliability}

The evidence about reliability and validity of the quantitative measurement process was explained in the data collection instrument section in detail. In order to prove validity and reliability of the qualitative analysis, internal validity (persuasiveness), external validity (communicability), internal reliability (consistency) and external reliability (repeatability) works (LeCompte \& Goetz, 1982, cited by Yıldırım \& Şimşek, 2013, p. 289) were conducted.

Internal Validity (Credibility): The methods used to increase the internal validity of the study are long-term interaction, expert review and participant verification (Yildırım \& Şimşek, 2013). To ensure this, interviews were kept as long as possible in terms of time and an environment of trust was created by long-term interaction between the participant and the researcher to conduct a proper data collection process. On the other hand, two experts in the topic of this study and the qualitative research were consulted before finalizing the semistructured interview form, themes and codes and before the data collection and data analysis processes. Moreover, the data collection instrument was checked by two teachers chosen from the focus group to test its comprehensibility. Finally, the data was transcribed using a computer and the participants were asked to confirm whether the information communicated to them represent their ideas.

External Validity (Transferability): It is about whether the research results are adaptable to similar environments and situations and generalizable in form of experiences and examples (Yıldırım \& Şimşek, 2013). To ensure this, a detailed description was made 
through direct references to necessary situations and the researchers paid special attention to collecting data from different sources in line with the purposive sampling method.

Internal Reliability (Dependability): In order to increase internal reliability of the study, the researchers used the conceptual framework obtained as a result of the literature review to create the themes and sub-themes during the data analysis process, as mentioned before. Another method used to increase internal reliability of the study was ensuring consistency among independent coders. This is also a strategy that increases the research's rate of acceptability by others (Yıldırım \& Şimşek, 2013). Accordingly, an independent researcher participated in data analysis and coding process of the study. The analyses made and codes created by both researchers were taken into account and the reliability measured using the formula suggested by Miles and Huberman (1994, p. 64). According to Miles and Huberman (1994, p. 64), a result above $90 \%$ is sufficient to prove the reliability. In this study, reliability of the codes in the data analysis was found to be $91 \%$ as a result of the calculations made with this formula.

External Reliability (Confirmability): One of the measures that should be taken to ensure external reliability of qualitative researches is to provide detailed explanations about data collection and analysis methods (Yıldırım \& Şimşek, 2013). In this regard, the enabling interview setting was preserved, the individuals who are the data sources of the study were clearly identified, detailed explanations were given about the way interviews were conducted, data were recorded, analyzed and results were presented.

\section{Findings}

This section presents findings about quantitative and qualitative dimensions of the study under six specific subtitles.

\section{Findings About the Study's Quantitative Dimension}

Score averages and standard deviation values that represent opinions of secondary school teachers about distributed leadership are given in Table 1.

Table 1. Score averages and standard deviation values about distributed leadership and its subdimensions $(\mathrm{n}=736)$

\begin{tabular}{lcccc}
\hline \multicolumn{1}{c}{ Subdimensions } & Minimum & Maximum & $\bar{X}$ & SD \\
\hline Formal Structure & 1.00 & 4.00 & 3.03 & 0.58 \\
Comman Goals & 1.13 & 3.75 & 2.77 & 0.47 \\
Cooperation and Trust & 1.00 & 4.00 & 3.07 & 0.57 \\
Shared Responsibility & 1.00 & 4.00 & 2.99 & 0.59
\end{tabular}


Encouragement and

Initiative

Total DL
1.00

1.09
4.00

3.91
2.96

2.95
0.62

0.49

According to Table 1, the participant teachers responded "I strongly agree" for the formal structure subdimension of distributed leadership at schools $(X=3.03)$, "I agree" for the comman goals subdimension $(X=2.77)$, "I strongly agree" for the cooperation and trust subdimension ( $X=3.07)$, "I agree" for the shared responsibility subdimension $(X=2.99)$, "I agree" for the encouragement and initiative subdimension $(X=2.96)$, and "I agree" to all questions in general $(X=2.95)$. Looking at the standard deviation values in arithmetic mean of teachers' responses, it is seen that these values are highly approximate. Accordingly, the most homogenous distribution is seen in the unity of purpose dimension $(S=0.47)$, while the most heterogenous distribution is seen in the motivation and initiative dimension $(S=0.62)$. According to teachers' opinions, the lowest degree of importance should be attached to the unity of purpose subdimension $(X=2.77)$, while the highest degree belongs to the cooperation and trust subdimension $(\bar{X}=3.07)$. On the other hand, results of the descriptive statistics regarding teachers' opinions about subdimensions of distributed leadership, the average score ranges of 27 schools analyzed within the study vary between $X=1.95$ and $X=3.36$.

\section{Findings About the Study's Qualitative Dimension}

This section presents the findings obtained as a result of the interviews, which were conducted to perform a detailed analysis of teacher's opinions from four different schools, with lowest and highest distributed leadership score averages, about distributed leadership and relevant concepts.

Findings about the general leadership/management approaches of schools according to the participant secondary school teachers are given in Table 2.

Table 2. Teachers' opinions about the leadership/management approach of their schools

\begin{tabular}{lll}
\hline Schools & Codes & $\mathbf{n}$ \\
\hline & *Mutual exchange of ideas and opinions & 12 \\
& ${ }^{*}$ Meetings with participation of all relevant stakeholders & 11 \\
& ${ }^{*}$ A supportive approach for employees & 10 \\
& *A democratic management approach & 9 \\
HLDL & *Inclusion of all stakeholders within the process & 8 \\
& *Teamwork & 7 \\
& *Support for those in leader positions & 7 \\
& *Leadership by expertise & 5 \\
& *Focusing more on practices than documents & 5 \\
& *Ignoring intra-organizational statuses & 5 \\
\hline
\end{tabular}




\begin{tabular}{llc} 
& Çakır \\
\hline & *Prioritizing institutionalism & 5 \\
& *Participation in management & 3 \\
& $*$ A transparent management approach & 2 \\
& *Voluntary task sharing & 2 \\
\hline & ${ }^{*}$ The principal as the sole authority & 9 \\
LLDL & *A so-called democracy-like autocracy approach & 9 \\
& ${ }^{*}$ Meetings are limited to briefings & 8 \\
& *Teachers and vice-principals as neutral elements & 5 \\
\hline
\end{tabular}

According to Table 2, teachers in the HLDL (High Level Distributed Leadership) group used terms of democratic management approach $(n=9)$, teamwork $(n=7)$, leadership by expertise $(n=5)$, participation in management $(n=3)$ and transparent management approach $(n=2)$ to define leadership/management approaches of their schools. Some relevant opinions mentioned by the participants are given below:

A democratic leadership approach dominates in our school. Our school takes students' ideas into account. Of course they are still children but at least they give us some ideas. We try to set the game up using students' opinions. Indeed, we distribute the leadership role by asking students' opinions. (HLDL1/T3)

Principals, vice-principals and teachers should be leaders. However, administrators may not have sufficient knowledge of all subjects. Therefore, leadership must be based upon expertise. This is an example of it. Leader teams are formed with experts in respective fields. (HLDL2/T6)

While giving examples about relevant practices they have observed at their schools, the participant teachers mentioned that schools organize meetings that all stakeholders participate in $(n=11)$, there is mutual exchange of ideas in these meetings $(n=12)$, any status given to each employee at organizational level is ignored $(n=5)$ and the attention is given to practices, rather than documents $(n=5)$. The following quote is important to see the situation clearly:

There is almost one meeting every single day at our school. We organize a branch meeting everyday. All participants of these meetings are relaxed and free. Everyone has the freedom of expression. The administrators take our opinions into account to ensure this. You can speak comfortably when you are being heard. But being heard does not suffice alone. Most importantly, all of our words are taken into consideration. What we say is valued. So we express all ideas and wishes comfortably. Otherwise, we would not try to consult them, nor speak out. We would not be willing to do something for the school. (HLDL2/T5)

The supportive approach of school administrators toward all employees $(n=10)$, inclusion of all stakeholders, including the students, in the process $(n=8)$ and the administrators' support for the leaders other than themselves $(n=7)$ are among the practices mentioned by the teachers. Prioritizing institutionalism $(n=5)$ and task sharing based on volunteering $(\mathrm{n}=2)$ are considered as facilitators of the process. One of the teachers summarized the general idea of all participants by saying: 
I was a leader at my school. In such environments, employees often act in solidarity. The administration always stands by us. That's because you create a plan or a schedule and need some stuff to realize it. Naturally, we consult administrators and ask them about "know-how" of tasks. And they, the administrators, help us without any hesitation. They do not opt to excessive questioning. That's because they trust us. (HLDL1/T1)

According to Table 2, teachers in the LLDL (Low Level Distributed Leadership) group defined leadership/management approaches of their schools as a democracy-like autocracy approach $(n=9)$. The opinions of participants can be summarized as follows:

A democracy-like autocracy approach is predominant. The principal is the sole authority at school. Teachers and vice-principals are like neutral elements. For example, teachers are consulted when an event is planned. But they are only consulted. The last decision is always taken according to the principal's will. In other words, it is a democracy-like autocracy. (LLDL2/T3)

The principal being the sole authority $(n=9)$, limiting meetings only with briefings $(n=8)$ and teachers and vice-principals who act as neutral elements $(n=5)$ are the practices/ideas mentioned by the participants in this regard. A participant summarized the situation as follows:

Meetings are limited to briefings. And in those briefings, we are consulted but not taken into consideration. All communication is based on business-like relations. The principal never comes into the teachers' room to have a talk with us. The last example was the board meeting we made during the seminar season. Other meetings were only to communicate the demands of the Ministry of National Education. In other words, they were only on paper. Besides these, we only gather in extreme (extra ordinary) situations, such as aids and extremely serious problems about students. (LLDL1/T5)

Findings about the development of common goals at school, according to the ideas of participant teachers, are given in Table 3.

Table 3. Teachers' opinions about the development of common goals at school

\begin{tabular}{lll}
\hline Schools & Codes & n \\
\hline & *Vision, mission and goals determined by the school principal & 11 \\
& and the strategic planning team & \\
& *Vision, mission and goals accepted by stakeholders & 9 \\
& *Success-oriented approach & 8 \\
& *Principal's willingness to monitor the process & 7 \\
& *Principal's efforts to make the vision, mission and goals touch & 7 \\
HLDL & the hearts of all stakeholders \\
& *Practices based on vision, mission and goals & 5 \\
& *Exploratory approach & 5 \\
& *Taking good practices as model & 4 \\
& *Achievable goals & 4 \\
& *Short-term plans created by teachers & 4 \\
& *High expectations & 3 \\
\hline & *Employees' unawareness of vision, mission and goals \\
LLDL & *On-paper vision, mission and goals determined by the school & 9 \\
& principal and the strategic planning team & 5 \\
\hline
\end{tabular}


Teachers in the HLDL group mentioned vision, mission and goals accepted by all stakeholders $(\mathrm{n}=9)$ and principal's efforts to make vision, mission and goals touch hearts of all stakeholders $(n=7)$ regarding the existence of common goals at respective schools. One of the participant teachers explained the situation as follows:

... In short, the vision, mission and goals touch the hearts of employees in a very effective way. This is a unique merit. The principal knows how to touch our hearts with these principles. Indeed, the process may sound authoritarian in this regard. However, the principal does such sensitive changes that touches our soul. And every time we see that helshe is right at the end. He/she even touches hearts of the parents in such a good way that they also do not object any decision. They know that all practices are for the common good. (HLDL2/T4)

Our school has a vision. We did not do anything to create a vision, but the principal communicated it to us in a touching and satisfactory way. All practices and conversations we have at school comes to the same point. We all act in accordance with our vision, mission and common goals. (HLDL1/T1)

Regarding the development and monitoring of common goals, teachers of the schools with high levels of distributed leadership practices stated that they have vision, mission and goals determined by the school principal and strategic planning team $(n=11)$; they have practices toward this vision, mission and common goals $(n=5)$; school principals monitor the process in an efficient way $(n=7)$; they are success-oriented $(n=8)$; they have an exploratory approach $(n=5)$; they take good practices as model $(n=4)$; they set achievable goals $(n=4)$; there are short-term goals developed by teachers $(n=4)$ and all employees and administrators have high expectancies $(n=3)$. Some relevant opinions mentioned by the participants are given below:

The vision, mission and strategic planning processes are jointly managed by the principal and the strategic planning team. We are success-oriented. We all focus on a common point. We focus on student success, as many other schools do. We have concerns about it. (HLDL2/T5)

There are a lot of devoted employees in our school. Our school focuses on raising both successful and moral students. We take good practices as a model. However, as we know that we can't do the same due to differences in materials, we adapt them to our situation. We act in accordance with our cultural level. We adapt them to Gaziantep. (HLDL2/T2)

According to Table 3, regarding the existence of a unity of purpose, teachers in the LLDL (Low Level Distributed Leadership) group stated that employees were not aware of the vision, mission and goals of respective schools $(n=9)$. For the development and monitoring of common goals, however, they said that there are only on-paper vision, mission and goals developed by the school principal and the strategic planning team $(n=5)$. A participant explained the situation as follows:

Of course, our school has a vision on paper. Every school has... But do we have an administrator who struggles to realize this vision? Unfortunately, no. Our administrators play safe. The vision of our school 
was not determined by us. And we even do not know who did this. Probably, it was developed by the planning team. After its development, no one communicated with us to say "we have such a vision. And we have to do these things to realize that". (LLDL1/T2)

Findings about the general cooperation and trust cultures of schools according to the participant secondary school teachers are given in Table 4.

Table 4. Teachers' opinions about cooperation and trust cultures of schools

\begin{tabular}{|c|c|c|}
\hline Schools & Codes & $\mathbf{n}$ \\
\hline \multirow{14}{*}{ HLDL } & ${ }^{*}$ Mutual respect & 11 \\
\hline & *Solidarity & 11 \\
\hline & ${ }^{*}$ Cooperation to find solutions to problems & 10 \\
\hline & ${ }^{*}$ Enhanced communication & 10 \\
\hline & *Exchange of information and experience & 10 \\
\hline & ${ }^{*}$ Organizational culture & 9 \\
\hline & *Environment of trust & 9 \\
\hline & ${ }^{*}$ Confidence in terms of profession's efficacy & 9 \\
\hline & *Strong relations with partner organizations & 6 \\
\hline & *Honesty & 4 \\
\hline & *Immediate response to problems & 3 \\
\hline & *Taking mistakes seriously & 3 \\
\hline & $\begin{array}{l}\text { *Importance attached to out-of-school social and cultural } \\
\text { activities }\end{array}$ & 3 \\
\hline & ${ }^{*}$ Target-oriented approach & 2 \\
\hline \multirow{7}{*}{ LLDL } & ${ }^{*}$ Mutual respect among teachers & 9 \\
\hline & ${ }^{*}$ Mutual trust among teachers & 8 \\
\hline & ${ }^{*}$ Trusting professional competence of colleagues & 7 \\
\hline & $\begin{array}{l}\text { *Poor communication between school administration and } \\
\text { employees }\end{array}$ & 7 \\
\hline & *Solidarity among teachers & 6 \\
\hline & *Exchange of information and experience among employees & 5 \\
\hline & ${ }^{*}$ Cooperation to find solutions to problems & 5 \\
\hline
\end{tabular}

Teachers in the HLDL group mentioned the mutual respect $(n=11)$, cooperation to find solutions to problems $(n=10)$, solidarity $(n=11)$, exchange of information and experience among employees, including administrators $(n=10)$, the environment of trust within the organization $(n=9)$ and the confidence among teachers in terms of efficacy in profession $(n=9)$ to explain the cooperation and trust relationships.

My colleagues are highly equipped in terms of the professional competence. I trust all my friends for their efficacy. Our success also proves that. There is a good exchange of information and experience among employees of our school. This can also be considered as proof of our mutual trust in terms of professional competence. We deliver the course subjects in parallel with one another. Indeed, it is not peculiar to us. This applies to the other branches, as well. We have an efficient cooperation among teacher groups. We act in cooperation. (HLDL1/T4)

..... We respect each other. No right is infringed here. No freedom is limited. If my colleagues had problems in professional competence, our school would not be such successful today. You will see this when you consider the success level of our school. The results we have achieved show whether the employees are competent in this profession. We also know that a number of teachers also have enrolled their children in this school. My child also studies here. (HLDL1/T3) 
According to the teachers, the enhanced communication $(n=10)$, the organizational culture $(n=9)$, honesty $(n=4)$, strong relations with partner organizations $(n=6)$, immediate response to problems $(n=3)$, taking mistakes seriously $(n=3)$, the importance attached to out-of-school social and cultural activities $(n=3)$ and the target-oriented approach $(n=2)$ are facilitators of the process.

We address even the closest friends at school as "mister" or "ma'am" or "teacher". We turned this attitude into an organizational culture. All employees of our school are honest people. No one decides on a penalty, even for the students, without consulting others. We write down even a minor mistake made by the students. For instance: "Ahmet hit Ali today". We immediately respond to such occasions. We never ignore them. Due to this monitoring, the students think that they are valued. This increases their selfconfidence. Those who make mistakes see that they are not ignored and thus do not repeat the problematic behavior. Teachers and parents are the biggest supporters of us in this process. (HLDL1/T5)

According to Table 4, some teachers in the LLDL (Low Level Distributed Leadership) group mentioned the mutual respect among teachers $(n=9)$, poor communication between school administration and employees $(n=7)$ and solidarity among teachers $(n=6)$ to explain the cooperation and trust relationship among the employees of respective schools. A participant explained the situation clearly as follows:

There is an efficient communication among teachers. We organize dinners. We listen to problems of each other. We help each other as much as we can. We try to find solutions. The teachers absolutely respect each other. We support each other. (LLDL1/T4)

Regarding the trust among employees, some teachers in the LLDL group emphasized the mutual trust among teachers $(n=8)$ and trust about professional competence of colleagues $(n=7)$.

I don't think that my colleagues have problems in terms of professional competence. They all do the best they can. They always prepare before a lesson. I see that. I strongly trust my colleagues in terms of knowledge and skills. (LLDL2/T1)

Exchange of ideas and experience among employees $(n=5)$ and cooperation to find solutions to problems $(n=5)$ are among the factors mentioned by the participants. A participant summarized the situation as follows:

There is an exchange of information and experience among employees in our school. We help each other particularly with our previous experiences. We talk about occasions we witnessed in the past. We give examples to similar situations. In our school, often a specific person is assigned to solve a problem. For instance, I have to solve the problem if it's about my class. In case of failure, I share it with my colleagues. If they also cannot find a solution, we consult the administration. So, there is a cooperative environment in our school. (LLDL1/T6)

Findings about the shared responsibility among schools' stakeholders according to the participant secondary school teachers are given in Table 5. 
Table 5. Teachers' opinions about the shared responsibility among schools' stakeholders

\begin{tabular}{lll}
\hline Schools & Codes & $\mathbf{n}$ \\
\hline & *Awareness of partnership & 8 \\
& *Awareness of the fact that stakeholders are significant to & 8 \\
& achieve success & \\
& *Cooperation among stakeholders in every respect & 7 \\
& *Stakeholders with sense of responsibility & 7 \\
& *A large scope of stakeholders & 7 \\
HLDL & *High level of parent participation & 6 \\
& *An administration with sense of responsibility & 5 \\
& *Stakeholder inclusion in problem solving & 4 \\
& *Awareness of being an official organization & 4 \\
& *Stakeholder visits & 3 \\
& *A legal point of view & 2 \\
\hline & *Parents' irresponsibility & 9 \\
LLDL & *Narrow scope of stakeholders & 9 \\
& *An administration with a focus on formalities rather than & 4 \\
\hline
\end{tabular}

Regarding the fulfillment of stakeholder responsibilities, teachers in the HLDL group emphasized the awareness of partnership $(n=8)$, awareness of the fact that stakeholders are significant to achieve success $(n=8)$, high level of parent participation $(n=6)$, cooperation among stakeholders in every respect $(n=7)$, stakeholders with sense of responsibility ( $n=7)$, an administration with sense of responsibility $(n=5)$ and the awareness of being an official organization $(n=4)$. A participant explained the situation as follows:

The parents of our students are well informed. Most of them visit the school regularly and follow the progress of their students closely. In case of a problem, we often get response from the parents within at most half an hour after the first call. This shows that they care about their children. Parent participation in teaching and learning processes is fairly high. They have a sense of responsibility. And they are aware that success can only be achieved with their support. (HLDL1/T4)

We organize parent visits to involve them in the process. That's because of the fact that we can't be successful if we can't unite and take responsibility. Even the workers and canteen staff of the school are stakeholders in this process. For example, school workers often accompany me when I'm on duty. They take responsibility. They take care of the students. They take care of classroom conditions. They often support us when we encounter a problem. (HLDL1/T5)

Some participants emphasized the wide range of stakeholders (the Ministry of National Education, neighborhood representatives, students, teachers, administrators, canteen staff, security staff, servants, parents) $(n=7)$, stakeholder inclusion in problem solving $(\mathrm{n}=4)$ and stakeholder visits $(\mathrm{n}=3)$. A participant explained the situation as follows:

The Ministry of National Education, neighborhood representatives, students, teachers, administrators, canteen staff, security officers, servants and parents are stakeholders of our school. For instance, the official representative of our neighborhood supports us on the Internet. He/she always promotes us. The municipality also supports us. They tell us about the current needs and help administrators take 
immediate actions. For instance, our vice principal can easily communicate with the Parks and Gardens Directorate and ask for assistance. I witnessed a few similar conversations. (HLDL2/T1)

On the other hand, some other teachers focused on a legal point of view $(n=2)$ and explained the situation as follows:

We can't move on without our stakeholders' support. Particularly, the support of parents... Each year we identify the school rules, according to relevant regulations, of course. We determine the rules of discipline. That means we also have a legal side. There is a decision maker at school. We prepare contracts about these issues. These contracts are sent to parents during the enrolment process. They are signed by both parents and students. In this way, no one can object us when we inflict consequences in case of a problem. We show the necessary contract if we encounter any objection. We say that the palest ink is better than the sharpest memory. To this end, we never skip these contracts. They help us gain support from parents. That's because they understand that we do our job in a conscious way. (HLDL1/T6)

Regarding the fulfillment of stakeholder responsibilities, teachers in the LLDL group emphasized the narrow scope of stakeholders (students, teachers, school administrators, the Ministry of National Education, parents), irresponsibility of parents $(n=9)$ and an administration with a focus on formalities rather than practices $(n=4)$. The opinions of participants can be summarized as follows:

Students, teachers, administrators, the Ministry of National Education, neighbors and parents are stakeholders of our school. However, we have serious problems about the parents participation. They act in a reckless misconduct. They don't take care of their children. They act insensitively. Some parents still do not come to the school after being called for five times. (LLDL2/T4)

We can consider being a stakeholder as being a partner. When you are a partner of something, you have to fulfill its requirements. You have to do your best to do the best. That's because it doesn't completely belong to you. You are a partner. However, teachers and administrators of our school often stand alone. Even the Ministry does not provide sufficient support. In general, we see that these partners are not aware of their responsibilities. (LLDL1/T1)

Findings about the encouragement of employees and relevant initiatives according to the participant secondary school teachers are given in Table 6.

Table 6. Teachers' opinions about encouragement and initiatives

\begin{tabular}{lll}
\hline Schools & Codes & n \\
\hline & *Facilitator role of the administration & 10 \\
& ${ }^{*}$ Encouraging employees to learn & 9 \\
& "Encouraging attitudes of administrators & 8 \\
& *Paying attention to professional development & 6 \\
& ${ }^{*}$ Guidance of administrators & 6 \\
HLDL & ${ }^{*}$ Employees can suggest ideas at any level (including students) & 6 \\
& ${ }^{*}$ Employees can take roles in different teams, commissions and & 6 \\
& boards & 6 \\
& ${ }^{*}$ Encouraging employees to take leadership roles & 5 \\
& "Counseling efforts of administrators & 4 \\
& ${ }^{*}$ Risk taking & 4 \\
\hline LLDL & ${ }^{*}$ Being a role model for employees & 7 \\
\hline
\end{tabular}


line with the wishes of school administrators

*The school administration only approves suggestions that are $\quad 7$

visually appealing

*The administration prevents employees from expressing

themselves

*The administration does not allow employees to undertake

leadership roles

${ }^{*}$ The administration does not support those who request to undertake leadership roles

Regarding the encouragement of employees and relevant initiatives, teachers in the HLDL group mentioned that the employees are encouraged $(n=9)$ and professional development is valued $(n=6)$ at schools.

The Professional development of teachers is valued by our school. For instance, seminar sessions are always productive for us. Every year, at the beginning of seminars, schools counselors organize trainings for us to address needs of the new 5th graders. They show us how to treat them. If there is no specific subject to discuss, we just talk about the books we enjoy reading with the school principal. The principal also delivers a subject in a seminar session. Our principal never feels uncomfortable with this situation. For instance, when we say "Mr. Principal, there is a training in .... I think we can adapt that to our school", he finds a way to and help us to realize this suggestion. (HLDL1/T2)

Participants also mentioned the encouraging behaviors of administrators $(n=8)$, employees that can suggest ideas at any level (including students) $(n=6)$ and risk taking $(n=4)$ in this regard.

Student can come to us and offer some activities, for example, something about the library. In this way, students guide us. They undertake leadership roles. They are aware that their ideas are valued. They are taken into account. (HLDL2/T1)

Some of the participants emphasized the facilitator role of the administration $(n=10)$, employees taking roles in different teams, commissions and boards $(n=6)$ and encouraging employees to take leadership roles $(n=6)$. The following quotations are significant in this way:

There is team work at our school. It is led by the school administrators. Everyone can offer a suggestion. First, these suggestions are assessed. Then the duties are distributed. Administrators also participate in this team work. That's because there is an official dimension of each activity. They rather manage this dimension. In other words, they facilitate our activities. So we never hesitate to take initiative. We bring ourselves to do this. (HLDL2/T5)

For instance, our principal came to watch all the matches of the team I have founded. This encourages me and makes me happy. He motivates us. He never leaves us alone. So we do not hesitate to do team work. We feel more confident due to the belief that the administration supports us. We find the courage to move on. (HLDL1/T4) 
Guidance of administrators ( $n=6)$, counseling efforts of administrators $(n=5)$ and being a role model for employees $(n=4)$ were among the practices mentioned by the teachers. For instance, a participant explained the situation as follows:

Our principal always encourages us to take leadership roles; helps us a lot in this regard, guides us, and supports us. Our principal shares his/her knowledge and experience with us. He/she does his/her best to help us succeed. He/she never lets us give in. He/she is a model for me and all other employees at school, in every respect. (HLDL1/T1)

According to Table 6, regarding motivation of employees and relevant initiatives, teachers in the LLDL group stated that teachers can only show the knowledge, abilities and skills in line with wishes of school administrators $(n=7)$, the school administration approves only visually appealing suggestions $(n=7)$, the administration prevents employees from expressing themselves $(n=4)$, the administration does not support those who request to undertake leadership roles $(n=4)$ and employees are not allowed to undertake leadership roles $(n=4)$. Some teachers explained this with the following words:

Teachers can only find opportunities to show their knowledge, abilities and skills when the administration allows. For example, our art teacher planned to organize an exhibition but could not find an enabling environment. The administration asked him to paint the school building. Our projects are rejected by the administration. So we do not try to take initiatives. (LLDL2/T5)

Some colleagues brought ideas to the administration about our self-development. All of them were rejected. So we do not take such initiatives any more. Generally, only sports activities are accepted by the administration. And that's only to win some cups or other prizes and promote the school. That's to say, only visually appealing suggestions are accepted. (LLDL1/T2)

\section{Discussion and Conclusions}

First of all, this study identified teachers' opinions about the subdimensions of distributed leadership (formal structure, comman goals, cooperation and trust, shared responsibility and encouragement and initiative). According to its results, teachers opinions about the comman goals subdimension show the lowest degree of importance when compared to others. Similarly, Joffreh, Mohammadi and Yasini (2012) conducted a study about the relationship between distributed leadership and the organizational cultural behavior and discovered that teachers' opinions about mission, vision and goals have the lowest degree of importance among all other subdimensions of distributed leadership. Joffreh et al. suggest that cumbersome structure, in other words, the excessive busyness seen at schools as the reason for this situation. On the other hand, according to Smith (2007), findings show that mission, vision and goals have the highest score average among all 
subdimensions of distributed leadership. In this study, Smith suggested that the inclusion of all employees and even the parents in the planning process of schools' vision, mission and goals as the reason behind this. This dimension of distributed leadership emphasizes the teachers' role in determination of vision, mission and goals of school and recognition of these factors by all stakeholders. From this point of view, it can be said that communication between the administration and the stakeholders when a vision and relevant goals are determined have a significant impact on recognition.

The results of the study show that teachers' score averages about the cooperation and trust subdimension of distributed leadership are higher than the others. Accordingly, Güçlü et al. (2015) analyzed opinions of vocational high school branch chiefs about administrators' distributed leadership approaches and found out that the cooperation between branch chiefs and teachers is high, and the cooperation between branch chiefs and administrators is at medium level. In addition, Korkmaz and Gündüz (2011) revealed that by analyzing the distributed leadership behaviors of primary school administrators, the school administrators develop collaborative relationships with the people they work together with. Looking at the foundations of the cooperation issue, which is seen in almost every study about distributed leadership, we will see jointly developed and recognized goals. Employees of an organization often cooperate to achieve these common goals. Although findings of the study reveal low score averages for the common goals subdimension, we can explain relatively high scores of cooperation with the fact that schools consider student success as an ultimate goal and adopt a student oriented approach in activities. In general, school administrations do not take satisfactory and solid measures to set common goals. However, all teachers work in cooperation to achieve this target.

Harris (2004a) analyzed the relationship between distributed leadership and school development and emphasized the importance of interpersonal relationships and the environment of trust. As a result, Harris suggested that lack of trust among employees and between employees and administrators would render the distributed leadership efforts ineffective. As a facilitator of distributed leadership, the environment of trust affects or is affected by cooperative activities. The level of trust among employees can either lead them to a successful cooperation or create an environment of distrust. From this point of view, cooperation and trust cannot be considered independent from each other as they are two interactive factors, affecting each other in either positive or negative way. Accordingly, it can 
be concluded that cooperative activities within institutions are sufficiently successful to affect the perception of trust among employees.

The first question addressed to the teachers during the interviews was on their opinions about leadership/management approaches of their schools. According to the outcomes of interviews made with the HLDL group, teachers define leadership/management approaches of theirs schools as leadership by expertise, democratic leadership and team work. In addition, teachers in the HLDL group also mentioned participation in management and a transparent management approach among others. On the other hand, a majority of those in the LLDL group regard management approaches of their schools as autocratic. Therefore, it can be concluded that schools with different levels of distributed leadership have different types of leadership/management approaches as well.

One of the four main distinctive characteristics of distributed leadership is that distribution depends on expertise. According to this understanding, leadership is maintained by a single person at the top, but distributed to different positions and fields of expertise. When these fields of expertise are brought together, it will be possible to create a dynamic that represents more than the whole group of participants (Bennett et al., 2003a, b; MacBeath et al., 2004; Woods et al., 2004). From this point of view, as mentioned by the participants, leadership by expertise and prioritization of expertise in practices are significant indicators of distributed leadership practices at respective schools.

Vroom and Yetton (1973) suggested that a democratic leadership can be realized by either consultation or participatory decision making (cited by: MacBeath et al., 2004). Spillane (2005) stated that a distributed perspective can be either democratic or autocratic in this regard, it can include all employees at a school but it may not be an absolutely democratic approach (Spillane, 2005). The findings obtained through the interviews support the idea that both democratic and autocratic management approaches can concurrently exist in distributed leadership. This differentiation can be explained with the differences in schools' reactions to external incidences. Hence, MacBeath et al. (2004) stated that an initiative can either be top to bottom or bottom to top approach and this is related to the context of the relevant school. However, as the autocratic approach was mentioned by only those in the LLDL group, regardless of their management techniques, these schools may lack the positive factors that build an enabling environment, such as being open to new ideas, which is highly significant in terms of mutual trust and freedom of expression. 
Teachers in the HLDL group also emphasized the concept of team work when talking about the leadership/management approaches of schools. According to Harris (2004a) and Ritchie and Woods (2007), team work is a key component of distributed leadership. However, team work does not suffice to indicate the existence of a distributed leadership model. In order to prove the existence of distributed leadership at a school, there must be some other components, such as unity of purpose, division of responsibility, motivation and initiative, participation in decision-making. Hence, this finding can only indicate a distributed leadership model together with the other components mentioned above.

Distributed leadership is a leadership approach that includes all relevant stakeholders, regardless of their organizational status which is often mentioned in the literature (Bennett et al., 2003a; Gronn, 2000; Gronn, 2002a; Spillane, 2005). When looking at the definition made by the participants about practices at their schools, we can see that the HLDL group often ignores organizational roles and statuses and it is seen in practices of schools, such as participation of all stakeholders, including students, in meetings. Moreover, the facts that all stakeholders can participate in decision-making, have freedom of expression, take roles based on experience or expertise, all of which refers to a democratic approach in management, are indicators of distributed leadership (Harris, 2004b; Spillane et al., 2001; Spillane, 2005). In this respect, democratic practices that include all stakeholders, task sharing based on volunteering, exchange of ideas during meetings and focusing more on practices than documents can be considered as indicators that prove teachers in the HLDL group can undertake leadership roles at schools and they are a part of the democratic management approach. In this regard, it should be stated that the most significant factor that encourage employees to undertake leadership roles is the support of administrators. There are studies about the importance of organizational support in initiatives within the relevant literature (Bennett et al., 2003a, b; Woods et al., 2004). Gronn (2002a) suggests that institutionalism is significant in facilitating the interpersonal cooperation. As mentioned by the HLDL group, institutionalism supports Gronn's idea in this respect.

Despite the practices of the HLDL group that ignores statuses, schools in the LLDL group generally adopt an autocratic management approach by organizing meetings for only briefing purposes, giving the sole authority to the school principal and regarding teachers and vice-principals as ineffective components in the process. These practices seen in schools with LLDL can be explained with the high rate of teacher circulation (turnover rate). In order 
to distribute their official leadership roles and authorities, the administrators should know the employees very well. Otherwise, it is highly challenging to ensure and achieve the transition to democratic practices (Harris, 2004a).

Organizational goals that are in line with the vision jointly created by all of the school's stakeholders and accepted by all are significant in the efficiency of the distributed leadership approach (Davis, 2009; ESHA, 2013; Gordon, 2005; Spillane, 2005). Likewise, as a result of their studies, MacBeath et al. (2004) and Singh (2014) stated that shared goals are encouraging factors. In this current study, teachers in the HLDL group stated that they have a common vision, mission and goals which are determined by school principals and strategic planning teams, however, these vision, mission and goals are communicated by school principals in such a way that touches all stakeholders, including the parents of students. They regard the common concerns among all stakeholders as an indicator of this environment. In this regard, considering the leadership/management approach at high-level schools which does not include all stakeholders in the process of goal setting, it can be said although the school does not adopt a democratic approach in this sense, it is sufficient for school administrators to help the stakeholders internalize them to meet on a common ground. It can also be seen in practice of schools with LLDL as they have also have common goals determined in a similar process but most of their stakeholders are unaware of them. Moreover, a majority of the participant teachers emphasized that these so-called goals are only on paper and not realized in fact. However, having common goals would help an organization build consensus, solve conflicts and create a culture of accommodation. Therefore the decision-making mechanism would work effectively (MacBeath et al., 2004). MacBeath's idea becomes meaningful when the existence and determination of common goals in school with LLDL are considered together with the autocratic approach mentioned by the participants.

On the other hand, teachers in the HLDL group emphasized that school principals monitor the processes in an efficient way, unlike principals of other schools. The finding of MacBeath et al. (2004) which suggests that it is challenging to create and realize new ideas without supervising teachers is in line with findings of this study. In this respect, it can be suggested that school administrators should monitor and evaluate the processes in an efficient way and thus, accountability has a significant role in distribution of leadership. Another finding of the study is that all employees and administrators have high 
expectations. Likewise, Grenda (2011) and ESHA (2013) emphasized that high expectations should be taken as the baseline in distribution of leadership.

In terms of common goals, the organization's perspective toward learning is another point to emphasize. A learning culture is necessary to achieve the capacity required for the distributed leadership (MacBeath et al., 2004). For schools with HLDL, the need for an approach to take good practices as a model through an exploratory attitude can be explained by existence of a learning culture in these schools. Moreover, the achievable goals of schools with HLDL can be accepted as an indicator of the fact that administrators of these schools act in line with their own capabilities by efficiently monitoring the process.

The topics that were agreed upon by teachers of both high level and low level schools when explaining the cooperation and trust relationships among employees are; mutual respect, environment of trust in organization, exchange of knowledge and experience among all employees including administrators and the confidence among teachers in terms of professional efficacy of each other. Looking at the literature about distributed leadership, a culture based on mutual respect and trust among employees (ESHA, 2013; Grenda, 2011; Harris, 2002; MacBeath et al., 2004), all kinds of cooperation and participation integrated in school culture and daily routines (Gronn, 2002b) are the factors that facilitate distributed leadership. On the other hand, the quality of communication and the collegiality, which were mentioned by the participants from schools with HLDL, also among the facilitators emphasized by MacBeath et al. (2004). According to findings of this study, the importance attached to out-of-school social and cultural activities can be described as a positive outcome of communication and a return of the enhance organizational culture frequently mentioned by the HLDL group. The reason for the similar codes revealed in both schools with HLDL and LLDL can be explained with the possibility that school administrators have relatively partial impact on this dimension compared to the others.

The most significant issue mentioned by the LLDL group is about the communication between school administrators and employees. According to this finding, miscommunication can be explained as an obstacle to distributed leadership. In relation to that, Harris (2004a) states that the success of distributed leadership at a school depends on a number of different factors, such as relations between other teachers and school administrations. It is important for teachers to develop productive relations with school administrations. A contrary case 
may result in discrimination between the teachers who undertake leadership roles and those who do not and thus lead to conflicts.

The relatively larger scope of leadership, which is a distinctive characteristic of distributed leadership, is associated with leadership practices both inside and outside the organization. Likewise, a study in the OECD about school leadership points out the importance of leadership at the system level so as to enhance cooperation both in internal and external networks and the resource allocation among different communities. According to ESHA (2013), distributed leadership is the approach that could lead us to this kind of leadership within the current system. In this respect, participants' emphasis on current strong relations between schools and partner organizations comes into prominence. According to this finding, distributed leadership can be considered as an effective step on the way to leadership at the system level.

Participants from schools with high levels of distributed leadership mentioned wider scopes in terms of partnership. Regarding the responsibilities of stakeholders, considering the Ministry of National Education, students, teachers, administrators, parents and even neighborhood representatives as stakeholders of the process is a significant step to have a larger scope that may facilitate the process in terms of distribution of leadership practices. Studies from the relevant literature suggests that including parents in the process and considering them as responsible as employees support this aforementioned finding (Elmore, 2000; ESHA, 2013; Gordon, 2005; MacBeath et al., 2004). In this respect, it is important for the stakeholders to act with the sense of responsibility. Likewise, the responses of participants from schools with HLDL about the awareness of partnership, the stakeholder awareness of being a facilitator of success and the sense of responsibility were relatively positive. A "high level of parent participation", "sense of responsibility in school administration" and "stakeholder solidarity to solve problems" can be examples for the main practices in this regard.

The impacts of cooperation among stakeholders (Gronn, 2002b) and the positive communication (Grenda, 2011) should not be ignored in discussions about the sense of responsibility. Participants from schools with HLDL emphasized these two points and stated that a positive environment of communication increases enhances cooperation. In this regard, positive relations with stakeholders can be considered as a facilitator of cooperation among them. 
The stakeholder visits and legal dimension seen in the schools with HLDL are also considered as effective factors in fulfillment of stakeholder responsibilities. It is also known that the mutual accountability is a significant factor in holding employees responsible for their performance (Elmore, 2000; ESHA, 2013; MacBeath et al., 2004), as well as undertaking and fulfillment of stakeholder responsibilities (MacBeath et al., 2004). In this regard, the legal dimension of a school can be considered as a facilitator with regard to holding employees responsible and helping them undertake and fulfill responsibilities. However, regarding fulfillment of stakeholder responsibilities, it is interesting to see that participants from schools with LLDL stated that their schools prioritize formalities rather than practices. In this regard, in opposed to the former example, the legal dimension poses an obstacle to distributed leadership.

Regarding the encouragement of employees and relevant initiatives, interestingly, all stakeholders of the schools with HLDL, including the students, can produce and initiate their own ideas. Considering the cultural distribution factor emphasized by MacBeath et al. (2004) from a taxonomic perspective, it can be suggested that the idea of distribution has already been integrated into school cultures as stakeholders can initiate their own ideas. The structures that allow employees to take roles in more than one commission or board constitute another indicator of the entrepreneurial spirit seen in distributed leadership (Harris, 2004b; Spillane et al., 2001; Spillane, 2005). Findings of this current study show that employees of the schools with HLDL can take part in different teams, commissions and boards. In this regard, we can suggest that the schools with high levels of distributed leadership provide better leadership opportunities for employees and the relevant efforts often bring benefits for organizations. According to the opinions of participants, "risk taking" is another point in terms of entrepreneurship at schools. Taking risks by allowing employees to show their knowledge, skills and expertise in an environment of mutual respect may lead an organization to acquire new learnings. Supportively, ESHA (2012) stated that it is necessary not to settle with the steps taken until today but also to test them by taking realistic risks.

According to the participant teachers, taking vocational education into account, motivating employees toward learning and adopting encouraging attitudes in this regard, the facilitator role of administrations and encouraging employees to take leadership roles, which are seen in schools with HLDL, are the conditions that lay a foundation for an 
entrepreneurial spirit. Looking at the relevant literature, Bennett et al. (2003a, b), Woods et al. (2004) and Williams (2011) emphasize the significance of an approach that attaches importance to professional development of school administrations and employees and thus provides access to leadership development opportunities for all employees and enables them to experience leadership. In this regard, it can be suggested that motivating employees to learn more and contributing to their professional development, encouraging them to undertake leadership roles and facilitating the relevant processes with a result-oriented approach boost the entrepreneurial spirit. Harris's (2004a, b) emphasis on improvement in the collective human capacity in an organization also supports this idea as a factor that may facilitate distribution of leadership by boosting entrepreneurship.

Another point mentioned by the participants from the schools with high levels of distributed leadership is counseling and guidance of administrators. Elmore (2000) and MacBeath et al. (2004) suggest that, in order to ensure a consistent whole, counseling and guidance in distribution of leadership should be provided by the school leader, within the scope of organizational expertise. According to them, this will also give people confident in distribution of leadership by raising the awareness that a strong and official leader exists. Although a cultural distribution that stipulates employees' own initiatives in leadership is preferred in distribution of leadership, the model where the initiative belongs to an official leaders and employees welcome the leader's guidance and counseling is also acceptable. Another finding that the study explored in schools with HLDL is that administrators of these schools are often good role models for employees. A pattern of expected behaviors to be created by administrators can be considered as a stimulant for employees. Elmore's (2000) suggestion that it is necessary for leaders to do or to pretend to do whatever they expect from others also supports this finding.

During the interviews, regarding decision-making processes at schools, teachers from the schools with high levels of distributed leadership stated that administrators value opinions of employees, teachers, students, other employees and parents do not hesitate to express opinions, administrations are effective in decisions about the school in general and employees can take decisions by using initiative. Looking at the literature, a study conducted by the Hay Group in 2003, suggested that the process of decision-making and taking initiative is flexible and an initiative can either be top to bottom or bottom to top process. In this respect, besides the practices that help employees' opinions be valued and allow them to 
express opinions without hesitation, the facts that the initiative in decisions are taken only by them and in situations that affect the whole school, initiatives are taken by administrations can be considered proving the flexibility of process. Moreover, common decisions taken by all stakeholders are also emphasized by teachers of high level schools. Inclusion of all stakeholders in decision-making mechanisms can be mentioned as a frequently emphasized democratic practice of schools.

The trust in decisions regardless of the makers, persuasive characteristic of decisions taken by administrations and the impact of the sense of responsibility on participation in decision-making are the other subjects mentioned by teachers from the HLDL group. According to Jaimes (2009), distributed leadership enhances teachers' sense of responsibility in decision-making processes. This finding is consistent with the one obtained in this study. Therefore, the high sense of responsibility observed in stakeholders of schools with HLDL can be considered as a positive factor in participation in decision-making. Moreover, as it is mentioned above, the professional trust between all employees and administrations of the schools with HLDL can be considered as a facilitator of the trust for decisions and decisions' persuasiveness.

The fact that decisions are taken by school administrations in the LLDL group is important in the sense that it is consistent with the autocratic approach seen in their leadership/management practices. Moreover, it can be suggested that administrators do not include employees in decision-making processes as they do not know them well enough. In this respect, Harris (2004a) stated that transition to distributed leadership model could be challenging when administrators do not know employees well enough. Finally, it can be emphasized that the high teacher turnover rate is another significant obstacle to distributed leadership practices.

\section{References}

Adıgüzelli, Y. (2016). Dağıtılmış liderlik ile örgütsel güven arasındaki ilişkinin öğretmen görüşlerine göre incelenmesi [Examining the relationship between distributed leadership and organizational trust according to opinions of teachers]. Eğitim ve Bilim [Education and Science], 41(185), 269-280.

Ağırdaş, Y. (2014). Resmi liselerde dağıtımo liderlik ile iş doyumu arasındaki ilişkinin öğretmen görüşlerine dayal olarak incelenmesi (Çorum örneği), [The examination of the relationship between distrubuted leadership and job satisfaction in public high schools based on the opinions of the teachers (Case of province of Çorum)], (Yüksek Lisans Tezi), [Dissertation Masters 
Thesis]. Okan Üniversitesi, Sosyal Bilimler Enstitüsü, İstanbul [Okan University, Institute of Social Sciences, İstanbul].

Arabacı, İ. B.; Karabatak, S. \& Polat, H. (2016). Ortaöğretim okulu yöneticilerinin dağıtımcı liderlik rollerine ilişkin öğretmen algıları [The perceptions of teachers on secondary school administrators' distributional leadership roles]. Kastamonu Eğitim Dergisi [Kastamonu Education Journal], 24(3), 1015-1032.

Archer, M. (1995). Realist social theory: The morphogenetic approach. Cambridge: Cambridge University Press.

Avolio, B. J. (2011). Full range leadership. Los Angeles: Sage Publications.

Baloğlu, N. (2011a). Dağıtımcı liderlik: Okullarda dikkate alınması gereken bir liderlik yaklaşımı [Distributed leadership: A leadership approach that should be taken into account in the schools]. Ahi Evran Üniversitesi Eğitim Fakültesi Dergisi [Ahi Evran University Journal of Kirşehir Education Faculty], 12(3), 127-148.

Baloğlu, N. (2011b). Dağıtımcı liderlik uygulamaları: Eklektik bir tasarım çalışması [An eclectic design study on implementations of distributed leadership]. Ahi Evran Üniversitesi Kırşehir Eğitim Fakültesi Dergisi (KEFAD) [Ahi Evran University Journal of Kırşehir Education Faculty], 12(4), 163-181.

Baloğlu, N. (2012). Değerler temelli liderlik ile dağıtımcı liderlik arasındaki ilişkiler: Okul müdürünün davranışını değerlendirmeye dönük nedensel bir araştırma [Relations between value-based leadership and distributed leadership: A casual research on school principles' behaviors]. Kuram ve Uygulamada Ĕgitim Bilimleri [Educational Sciences: Theory \& Practice], 12(2), 1367-1378

Bennett, N., Wise, C., Woods, P. A. \& Harvey, J. A. (2003a). Distributed leadership: A review of literature. National College for School Leadership (NCSL). Source: http://www.rtuni.org/uploads/docs/Distributed\%20Leadership\%20-\%20review.pdf

Bennett, N., Wise, C., Woods, P. A. \& Harvey, J. A. (2003b). Distributed leadership: A review of literature summary report. National College for School Leadership (NCSL). Source: http://www.learnersfirst.net/private/wp-content/uploads/Resource-DistributedLeadership-Report-Summary-2003-NCSL.pdf

Bolden, R., Petrov, G. \& Gosling, J. (2009). Distributed leadership in higher education. Educational Management Administration and Leadership, 37(2), 257-277. Source: http://dx.doi.org/10.1177/1741143208100301

Büyüköztürk, Ş., Kılıç Çakmak, E., Akgün, Ö. E., Karadeniz, Ş. \& Demirel, F. (2012). Bilimsel araştırma yöntemleri [Scientific research methods]. Ankara: Pegem Akademi Yayınları [Ankara: Pegem Akademi Publishing].

Camburn, E.; Rowan, R. \& Taylor, J (2003). Distributed leadership in schools: The case of elementary schools adopting comprehensive school reform models. Educational and Policy Analysis, 25(4), 347-373.

Chen, Y. (2007). Principals' distributed leadership behaviors and their impact on student achievement in selected elementary schools in Texas. (Unpublished doctoral dissertation). Office of Graduate Studies of Texas A\&M University, USA.

Clark, A. (2007). The handbook of school management. Cape Town: Macmillan. 
Creswell, J. W. (2012). Educational research: Planning, conducting, and evaluating quantitative and qualitative research. Boston: Pearson Education, Inc.

Creswell, J. W. (2013). Qualitative inquiry and research design: Choosing among five approaches (Bütün, M. and Demir, S. B., Çev.). Ankara: Siyasal Yayın Dağıtım.

Creswell, J. \& Plano Clark, V. L. (2007). Understanding mixed methods research. In J. Creswell (Eds.), Designing and conducting mixed methods research (pp. 1-19). Thousand Oaks, CA: Sage.

Davis, M. W. (2009). Distributed leadership and school performance (Unpublished doctoral dissertation). George Washington University, The Graduate School of Education and Human Development, USA.

Drucker, P. F. (1959). Landmarks of tomorrow: A report on the new "Post-Modern" world. New York: Haper \& Bros.

Elmore, R. F. (2000). Building a New Structure For School Leadership. The Albert Shanker Institute, Winter, $2000 . \quad$ Source: http://www.shankerinstitute.org/sites/shanker/files/building.pdf

ESHA (2012). Position paper distributive leadership. Utrecht: ESHA.

ESHA (2013). Distributed leadership in practice: A descriptive analysis of distributed leadership in European schools. 28 October, 2013. Source: http://josephkessels.com/sites/default/files/duijf_e.a. 2013 distributed leadership in p ractice esha-etuce $0 . \mathrm{pdf}$

Fiedler, F. E. (1964). A contingency model of leadership effectiveness. In L. Berkowitz (Eds.) Advances in experimental social psychology. New York: Academic Press.

Fielding, M. (1999). Radical collegiality: Affirming teaching as an inclusive professional practice. Australian Educational Researcher, 26(2), 1-34.

Gibb, C. A. (1947). The principles and traits of leadership. Journal of Abnormal and Social Psychology, 42(3), 267-284.

Gibb, C. A. (1954). Leadership. In G. Lindzey (Eds.) Handbook of social psychology (pp. 877-917). MA: Addison-Wesley.

Gordon, Z. V. (2005). The effect of distributed leadership on student achievement (Unpublished doctoral dissertation). Central Connecticut State University, Connecticut. DAI-A 66/12, June 2006, 101.

Grenda, J. P. (2011). Instances and principles of distributed leadership: A multiple case study of Illinois middle school principals' leadership practices (Unpublished doctoral dissertation). University of Illinois, Educational Administration and Leadership Graduate College, Urbana, Illinois.

Gronn, P. (2000). Distributed properties: A new architecture for leadership. Educational Management and Administration, 28(3), 371-388.

Gronn, P. (2002a). Distributed leadership as a unit of analysis. Leadership Quarterly, 13(4), 423-51. 
Gronn, P. (2002b). Distributed leadership. In K. Leithwood, P. Hallinger, K. Seashore-Louis, G. Furman-Brown, P. Gronn, W. Mulford and K. Riley (Eds.) Second international handbook of educational leadership and administration (pp. 1-48). Dordrecht: Kluwer.

Güçlü, N., Tınmaz, A. \& Paksoy, E. E. (2015). Meslek lisesi okul yöneticilerinin dağıtımcı liderlik özelliklerinin incelenmesine yönelik nitel bir araştırma [A qualitative research on the distributed leadership characteristics of vocational high school administrators]. VI. Uluslararası Türkiye Eğitim Araştırmaları Kongresi'nde sunulan bildiri [Paper presented at the VI. Turkey International Congress of Educational Research], Ankara, 2015.

Harris, A. (2002). Distributed leadership in schools: Leading or misleading? Source: http://journals.sagepub.com/doi/abs/10.1177/089202060301600504?journalCode=miea

Harris, A. (2004a). Distributed leadership and school improvement: Leading or misleading? Educational Management Administration Leadership, 32(1), 11-24. DOI: $10.1177 / 1741143204039297$

Harris, A. (2004b). Distributed leadership: Leading or misleading? Paper presented at the Annual Meeting of the American Education Research Association, San Diego, CA. Source: https://www.aera.net

Harris, A. \& Muijs, D. (2005). Improving schools through teacher leadership. New York: Open University Press.

Hay Group Education (2003). Growing tomorrow's school leaders: The challenge. Source: http://www.haygroup.com/Downloads/uk/misc/Growing Tomorrows School Leaders . $\mathrm{pdf}$

Heck, R. H. \& Hallinger, P. (2009). Assessing the contribution of distributed leadership to school improvement and growth in Math achievement. American Educational Research Journal, 46(3), 659-689. DOI: 10.3102/0002831209340042

Jaimes, I. J. (2009). Distributed leadership practices in schools: Effect on the development of teacher leadership a case study (Unpublished doctoral dissertation). University of Southern California, California.

Joffreh, M., Mohammadi, F. \& Yasini, A. (2012). Leadership distribution consequences in schools: A particular look at organizational citizenship behavior of teacher. Australian Journal of Basic and Applied Sciences, 6(12), 259-268.

Johnson, R. \& Onwuegbuzie, A. (2004). Mixed methods research: A research paradigm whose time has come. Educational Researcher, 33(7), 14-26.

Karasar, N. (2012). Bilimsel araştırma yöntemi [Scientific research method]. Ankara: Nobel Yayıncılık [Ankara: Nobel Publishing].

Kılınç, Ç. (2014). A quantitative study of the relationship between distributed leadership and organizational citizenship behavior: Perceptions of Turkish primary school teachers. Journal of Curriculum and Teaching, 3(2), 69-78.

Korkmaz, E. \& Gündüz, H. B. (2011). İlköğretim okulu yöneticilerinin dağıtımcı liderlik davranışlarını gösterme düzeyleri [Indiceting levels of distributive leadership behaviours of primary school principals]. Kalem Ĕ̆itim ve İnsan Bilimleri Dergisi [Kalem International Journal of Education and Human Sciences], 2011(1), 123-153. 
Kotter, P. J. (1990). What do leaders really do? Harvard Business Review, 79(11), 85-96.

MacBeath, J., Oduro, G. \& Waterhouse, J. (2004). Distributed leadership in action: Full report. Source: www.ncsl.org.uk

Mahoney, P. \& Moos, L. (1998). Democracy and school leadership in England and Denmark. British Journal of Educational Studies, 46(3): 302-17.

Miles, M. \& Huberman, M. (1994). An expanded sourcebook qualitative data analysis. California: Sage Publications.

Özdemir, M. (2012). Dağıtımcı liderlik envanterinin Türkçe uyarlaması: Geçerlik ve güvenirlik çalışmaları [Turkish adaptation of Distributed Leadership Inventory: The validity and reliability studies]. Kuram ve Uygulamada Eğitim Yönetimi [Educational Administration: Theory and Practice], 18(4), 575-598.

Özkan, M. \& Çakır, Ç. (2017). Dağıtılmış Liderlik Ölçeği'nin geliştirilmesi [development of Distributed Leadership Scale]. Uluslararası Avrasya Sosyal Bilimler Dergisi [International Journal of Eurasia Social Sciences], 30 (8), 1629-1660.

Pounder, D. G., Ogawa, R. T. \& Adams, E. A. (1995). Leadership as an organization wide phenomenon: Its impact on school performance. Educational Administration Quarterly, 31(4), 564-588.

Printy, S. (2008). Distributed Leadership: A Quick Tour of Theory and Practice, Michigan Principal's Fellowship. Michigan Principals Fellowship Summer Institute.

Ritchie, R. \& Woods, P. (2007) Degrees of distribution: Towards an understanding of variations in the nature of distributed leadership in schools. School Leadership and Management, 27(4), 363-381

Singh, S. (2014). The impact of distributed leadership practices on the functioning of primary schools in Johannesburg South (Master's thesis). University of South Africa, Education Management, Johannesburg.

Smith, L. M. (2007). Study of teacher engagement in four dimensions of distributed leadership in one school district in Georgia (Electronic thesis \& dissertations, Georgia Southern University, Georgia). Source: https://digitalcommons.georgiasouthern.edu/cgi/ viewcontent.cgi ?referer=https://www.google.com.tr/\&httpsredir=1\&article=1282\&context=etd

Smylie, M. A. \& Denny, J. W. (1990). Teacher leadership: Tensions and ambiguities in organizational perspective. Educational Administration Quarterly, 26(3), 235-259.

Spillane, J. P. (2005). Distributed leadership. Educational Forum, 69(2), 143-150.

Spillane, J. P. (2006). Distributed leadership. San Francisco: Jossey-Bass.

Spillane, J. P., Halverson, R. \& Diamond, J. B. (2001). Investigating school leadership practice: A distributed perspective. Research News and Comment, April, 2001, 23-28.

Wallace, M. \& Hall, V. (1994). Inside the SMT: Teamwork in secondary school management. London: Paul Chapman.

Williams, C. G. (2011). Distributed leadership in South African schools: possibilities and constraints. South African Journal of Education, 31, 190-200. 
Woods, P. A., Bennett, N., Harvey, J. A. \& Wise, C. (2004). Variabilities and dualities in distributed leadership: Findings from a systematic literature review. Educational Management Administration Leadership, 32(4), 439-457. DOI: 10.1177/1741143204046497

Yıldırım, A. \& Şimşek, H. (2013). Sosyal bilimlerde nitel araştırma yöntemleri [Qualitative research methods in the social sciences]. Ankara: Seçkin.

Yılmaz, D. \& Turan, S. (2015). Dağıtılmış liderliğin okullardaki görünümü: Bir yapısal eşitlik modelleme çalışması [Distributed leadership view in schools: A structural equation modelling study]. Kuram ve Uygulamada Eğitim Yönetimi [Educational Administration: Theory and Practice], 21(1), 93-126. 